\title{
MONITORAMENTO DOS CASOS DE SIFILIS EM UM AMBULATORIO ESPECIALIZADO EM IDOSOS
}

\section{Edna Kazuko Sasajima, Andréa Aparecida da Fonseca Monteiro, Joana D’arc Ricardo dos Santos, Marcia Maiumi Fukujima.}

\section{INTRODUÇÃO}

A sífilis é uma doença de notificação compulsória, e o número de casos vem aumentando entre os idosos. A solicitação desse exame para o idoso, é devido a investigação de déficit cognitivo a esclarecer e demência. A apresentação dos sinais e sintomas da doença é muito variável e complexa. Quando não tratada, evolui para formas mais graves, podendo comprometer o sistema nervoso, o aparelho cardiovascular, o aparelho respiratório e o aparelho gastrointestinal.

OBJETIVO: Monitorar, analisar causas e definir plano de ação voltados a melhoria da assistência aos idosos com o diagnóstico de Sífilis.

\section{DESENVOLVIMENTO}

Acompanhamento dos casos de suspeita de Sífilis foi implantado em janeiro de 2017. O paciente é notificado conforme preconizado pelo Ministério da Saúde e notificação é direcionada para SUVIS (Serviço de Unidade de Vigilância em Saúde). O fluxo do monitoramento dos casos se inicia após o resultado dos exames laboratoriais onde são sinalizados pelo laboratório os resultados alterados, as condutas são direcionadas de acordo com o plano definido nas discussões dos casos entre o médico e a enfermeira responsável. Para os casos direcionados para tratamento medicamentoso o enfermeiro responsável realiza contato com UBS de referência do paciente direcionandoo para aplicação do medicamento prescrito. Tratamento finalizado paciente retorna na unidade para consulta com a enfermeira trazendo copia da receita onde evidenciamos que o tratamento medicamento foi finalizado.

\section{RESULTADOS}

Durante os meses de janeiro a novembro de 2018 foram monitorados 97 exames com alteração, sendo 83 ( $86 \%$ ) casos de sífilis, 11 (11\%) de hepatite e 03 (4\%) de Doença de Chagas. As condutas relacionados a sífilis, $3 \%$ dos casos foram solicitados líquor como diferencial para tratamento, $14 \%$ receberam tratamento com antibiótico, conforme preconizado pela Secretaria de Saúde, e 83\% dos casos referem- se a cicatriz sorológica.
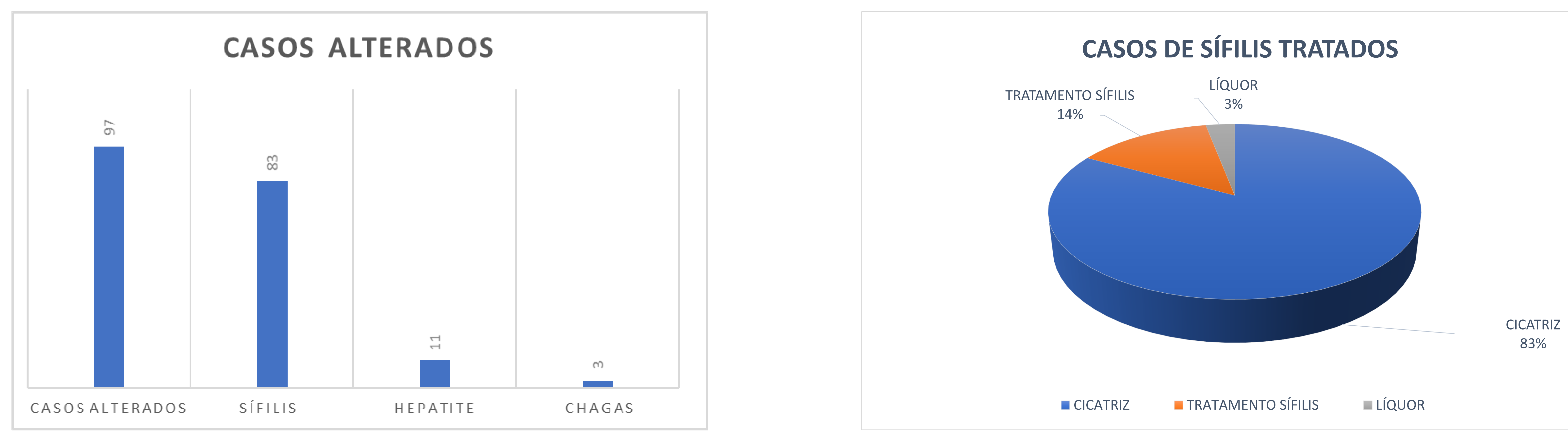

\section{CONCLUSÃO}

A atuação do enfermeiro para monitoramento é o diferencial para condução dos casos, por se tratar de profissional com competências para as discussões dos casos com a equipe medica e transmitir as informações e conduta definidas para o paciente. 0 trabalho realizado proporcionou melhoria no processo de acompanhamento dos casos de notificação compulsória na unidade.

\section{REFERÊNCIAS}

Brasil. Ministério da Saúde. Secretaria de Vigilância em Saúde. Coordenação-Geral de Desenvolvimento da Epidemiologia em Serviços. Guia de Vigilância em Saúde: volume 2 - 1. ed. atual. - Brasília: Ministério da Saúde, 2017 